\title{
Development of a method for reducing corrosion processes activity at water consuming facilities
}

\author{
Elena Moskvicheva ${ }^{1 *}$, Anton Timofeev ${ }^{1}$, Elena Kotovchikhina ${ }^{1}$, Viktor Batmanov ${ }^{1}$, and \\ Alexandra Nesterchuk $^{2}$ \\ ${ }^{1}$ Volgograd State Technical University (VolgSTU), 400074, Volgograd, Russia \\ 2 "North Caucasus Federal University" Institute of Service, Tourism and Design (branch) NCFU in \\ Pyatigorsk, 355009, Stavropol, Russia
}

\begin{abstract}
This article is devoted to the development of a method for reducing the activity of corrosion processes on the metal surfaces of water consuming facilities (hereinafter WCF). Today for WCF the following problem is acute: the existing corrosion protection does not provide the necessary completeness of reliability, thereby preventing them from being operated in accordance with the established standards. Corrosion damage is often the cause of large-scale pollution of hydrosphere and lithosphere. Therefore, the task of preventing or achieving a possible minimum of corrosion and biofouling formation intensity is to ensure the maximum protection efficiency, which is directly related to the search for new methods to reduce the corrosion processes activity.
\end{abstract}

\section{Introduction}

For WCF metal structures the most common are various inhibitors: sodium hexametaphosphate, sodium tripolyphosphate, sodium trisilicate, magno-mass (dolomite, double carbonate calcium salt and magnesium).

The use of the listed inhibitors is very problematic, because the way they are applied to the metal surface is not designed for the WCF considered operating conditions. The most satisfactory results were obtained from the tests with the use of ferrocene (the duration of action was 7-9 months, and, consequently, a sharp biomass (mollusks) growth began after a designated period of time). It should be noted that ferrocene and its homologues are not toxicants for water [1].

The problem of biofouling is mollusks and algae, but the primary role is assigned to algae as a nutrient medium. Among them, in freshwater aquatic environments, the leading role of Dreissena mollusks, for which a favorable environment is SRB - these are bacteria, which are the main constituent of biofilm, which is necessarily formed in the aquatic environment on surfaces from different materials (i.e., having a different chemical composition). Most active SRB growth is observed on the surface of products (structures) containing iron and, above all, Art. 20 [2].

\footnotetext{
${ }^{*}$ Corresponding author: viv_vgasu@mail.ru
} 
The presented article for the first time expounds a different, fundamentally opposite to the known, point of view on the processes occurring on the metals section surface (iron): biofilm (SRB). The authors have thoroughly investigated the material related to the physicochemical composition of the products of interaction SRB, conditions that catalyze certain reactions [3].

\section{Main part}

SRB is known as a group that unites eight genera of different bacteria, but more than $70 \%$ of them are unicellular and filamentous, which form in the course of their life, oxidizing iron $(\mathrm{Fe} 0-2 \mathrm{e}=\mathrm{Fe} 2+)$ biocatalysts for all types $\mathrm{SRB}$, biocatalysts for all types $\mathrm{Fe} 2+$ and then carried out an experimental search for a factor, the presence of which passives the metal surface of the head walls lattice in fresh natural water.

Under laboratory conditions, when working with model and real solutions, it was shown that the biosynthesis of catalysts from SRB accelerated if certain organic compounds are present in the environment: fatty acids (from 1 to 18 conventional designations, as well as their salts, alcohols (ethanol, propanol, butanol, carbohydrates (sugar, etc.), cyclic chlorinecontaining compounds) [4].

In this way, on the basis of the biofouling theoretical analysis, the causes of its occurrence, the main factors initiating it, it was established that biofeedback can be prevented if the foundations - areas for the initial colonies - microorganisms reproduction are transformed into passions, i.e., in this study, the maximum [5].

It is required to determine the factors (transfer conditions) capable of making the head grating surface inert.

On experimental samples, ferrocene turned out to be the most acceptable option. On the prepared surface it was applied in a thin layer in such a way that the drying time was minimal, then it was immersed in water and once worked. It was empirically verified, taking into account that pentadiene can be converted into anion and iron can be oxidized, an attempt to implement the synthesis of ferrocene on the lattice surface. Preliminarily, in the laboratory conditions, it was obtained from biomass collected from biofouling products, where an experimental sample was used as anode. Having taken the biomass of at least 150-170 g from the sample, it was placed in a chemical glass and a plate made of the steel under study was placed there. The experiment was carried out in an electrochemical cell with a separate anode and cathode space. Redox potential of alkenes in the range from +0.25 to $0.3 \mathrm{~B}[6]$.

Ferrocene - refers to organic derivatives. Its molecule has a "sandwich" structure, which probably ensures its high adhesion ability, and allows even with an inhibitor film thickness of $3 \mu \mathrm{m}$, the lattice metal surface to be kept in a passive state, thus practically stopping the growth SRB and further - biofeedback.

An experiment was carried out under laboratory conditions to identify the conditions for the inhibitor film formation, and then the biofouling process on the obtained surface was investigated.

The following was established: organic compounds of the class of cycloolefins included in the composition can serve as a raw material for obtaining a ferrocene film. SRB - auxins and prostaglandins (growth stimulants and regulators of cell function SRB). For IF (inhibitor film) formation with a thickness of at least $3 \mu \mathrm{m}$, the amount of biomass per 1 $\mathrm{cm} 2$ surface is required not less than $26-30 \mathrm{mg}$.

Under the anodic potential influence of $250-400 \mathrm{mV}$, the reaction most likely proceeds according to the ionic mechanism: cyclopentadiene and its homologues.

In SRB, although they do not possess an aromatic character and behave like unsaturated substances, they can form ions with typical aromatic properties - by splitting off a proton 
and preserving an electron pair, it turns into an aromatic cyclopentadienyl anion having a sextet dienyl.

Thus, the interrelation of SRB distribution with the content of dissolved organic substances in wastewater, mostly carbohydrates. SRB development in a number of experiments took place with an average content of organic matter in water of 9-33 mg / 1 . At a lower content of organic substances in the water, bacteria were not detected. Dissolved organic matter can be hydrocarbons, oils, nitrogen-containing substances, oxygencontaining compounds such as naphthenic, fatty acids, resins, humates $[7,8,9]$.

In the course of the experiment on the anodic treatment effect on the corrosion rate of Art. 20 shows that with a film thickness of at least $100 \mu \mathrm{m}$ and a current density of at least $0.01 \mathrm{~A} / \mathrm{dm} 2$ a number of reactions take place, including the reactions (1) and the reaction of obtaining a product from SRB components, forming with ion $\mathrm{Fe} 2+$ multinuclear ferrocenes, which are an oxidation-resistant film with high adhesion capacity on the steel surface (stage 20 ), which does not disintegrate for a long time (5-6 months) and is a favorable substrate for SRB on which the formation of sulfide deposits slows down. Chemical composition of inhibitors (ferrocenes): $\quad[\mathrm{Fe}(\mathrm{C} 5 \mathrm{H} 5)(\mathrm{CO}) 2] 2, \quad \mathrm{Fe}(\mathrm{C} 5 \mathrm{H} 5)(\mathrm{C} 6 \mathrm{H} 7), \quad(\mathrm{CO}) 3 \mathrm{FeC} 6 \mathrm{H} 7-$ $\mathrm{C} 6 \mathrm{H} 7 \mathrm{Fe}(\mathrm{CO}) 3, \mathrm{C} 5 \mathrm{H} 5 \mathrm{FeC} 5 \mathrm{H} 4 \mathrm{R}$, where $\mathrm{R}$ - radical including six-membered legend [10].

So, the availability of both ferrocene and its derivatives according to the developed technology creates a sufficiently reliable basis for the highly effective anticorrosive insulating materials' preparation.

To clarify the structural changes, compositions prepared on the basis of ferrocene and its OBL derivatives (I-IV) was used IR- spectral method.

Since it is believed that types FET-inhibitors become effective when, with the help of active centers, they coordinate with metals via a donor-acceptor bond, forming intermediate complexes, providing inhibition of further redox processes occurring on the surface of metals [11].

In order to identify more optimal compositions of anticorrosive insulation compositions based on LSL, of ferrocene and its derivatives, the corresponding compositions were prepared at the same molar ratios.

The anticorrosive efficiency of the obtained samples was determined by both the gravimetric and the potentiation method. Rust was formulated on the inoculated samples by soaking them with a $\mathrm{NaCl}$ solution and to accelerate its formation, these samples were regularly kept in the air after soaking. Then, the rust layer formed by such an image on the surface was scraped off and subjected to an X-ray phase study [12]. The obtained results are shown in Table. 1.

Table 1. Results of testing the inhibiting ability of ferrocene and dimethylphenylcarbinol in $3 \% \mathrm{NaCl}$

\begin{tabular}{|l|c|c|c|c|c|c|}
\hline No. & Solute & $\begin{array}{l}\text { Cinh, } \\
\mathrm{G} / \mathrm{L}\end{array}$ & $\begin{array}{l}\text { Corrosion } \\
\text { rate } \\
\mathrm{Kg} / \mathrm{m}^{2} \cdot \mathrm{hour}\end{array}$ & $\begin{array}{l}\text { Braking } \\
\text { ratio, } \gamma\end{array}$ & $\begin{array}{l}\text { Protection } \\
\text { Degree, Z, } \\
\%\end{array}$ & $\begin{array}{l}\text { Test } \\
\text { time, } \\
\text { hour }\end{array}$ \\
\hline 1 & $3 \% \mathrm{NaCl}$ & & 2.74 & - & - & 7 \\
\hline 2 & $\begin{array}{c}3 \% \mathrm{NaCl}+ \\
\text { dicyclopentadienyliron }\end{array}$ & - & 0.476 & 5.76 & 82.6 & 8 \\
\hline 3 & $\begin{array}{c}3 \% \mathrm{NaCl}+ \\
\text { dimethylphenylcarbinol }\end{array}$ & - & 0.310 & 8.84 & 88.7 & 8 \\
\hline
\end{tabular}

As it can be seen from the table, the minimum amount dissolved in $3 \% \mathrm{NaCl}$ contributes to a significant decrease in the corrosion rate of steel 20 in $3 \% \mathrm{NaCl}$. The 
inhibition coefficient of dicyclopentadienyliron and dimethylphenylcarbinol is 5.76 and 8.84 , and the protection degree is 82.6 and $88.7 \%$, respectively.

Figure 1 shows the polarization curves of reinforcing steel in $3 \% \mathrm{NaCl}$ and in inhibited solutions saturated with ferrocene and dimethylphenylcarbinol.

As it can be seen from the figure, the electrochemical behavior of steel 20 in $3 \% \mathrm{NaCl}$ corresponds to the behavior of carbon steels in neutral media, i.e., the cathode section of the polarization curve consists of oxygen reduction and hydrogen evolution, while the anode section consists entirely of the Tafel section of active metal dissolution (curves 1,1 '). The introduction of ferrocene into the solution shifts the stationary potential of steel to the positive side by about $50 \mathrm{mB}$, however, at the same time, the length of the cathode site increases, oxygen recovery, and the process of hydrogen evolution shifts towards more negative potentials, in comparison with the initial curve (compare curve 2 ' and curve 1'). One curve of significant changes does not endure (compare curve 2' and curve 1'), those. The slope of the Tafel site of anodic dissolution does not change significantly. Significant influence on the cathodic and anodic behavior of steel is exerted by the addition to the solution dimethylphenylcarbinol. In this case, the potential shifts significantly to the positive side by $0.13 \mathrm{~B}$, the rate of cathodic and anodic processes is significantly reduced, which indicates a more effective inhibition of dimethylphenylcarbinol corrosion processes.

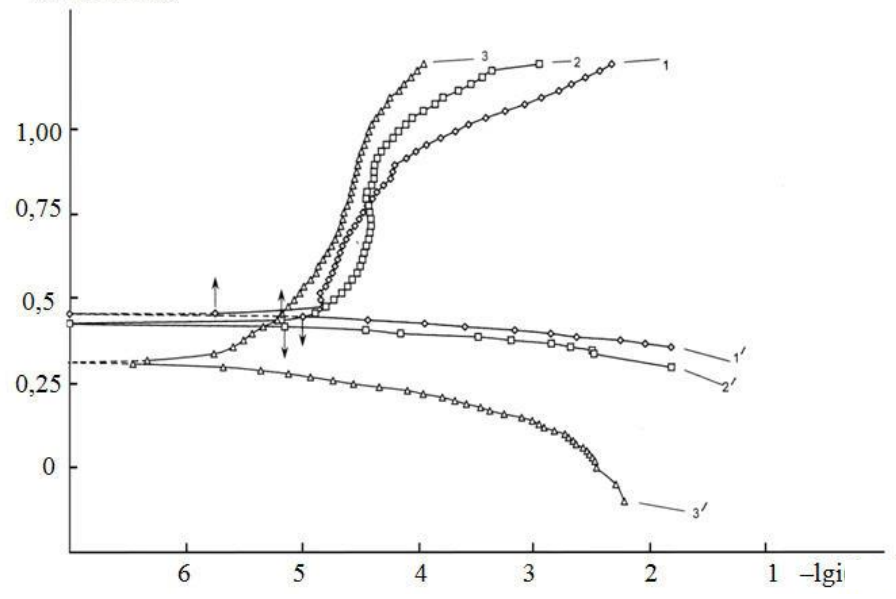

Fig. 1. Polarization curves of reinforced steel in $3 \% \mathrm{NaCl}\left(1.1^{\prime}\right)$ and in inhibited solutions saturated with ferrocene (2.2') and dimethylphenylcarbinol (3,3')

\section{Conclusion}

Apparently, existence functional $\mathrm{OH}$ - group in a dimethylphenylcarbinol molecule on the one hand slightly increases its solubility in water, and on the other hand improves the adsorption capacity of the molecule dimethylphenylcarbinol [13].

As noted above, one of the ways to protect metals from corrosion is to protect them by using paint and insulating coatings.

The results obtained are apparently due to several circumstances - the products of steel corrosion or interact with the coating components, forming new compounds; or the resulting mixture is not X-ray transparent. Regardless of the fact that which of these options takes place in reality, it can be assumed that rust in this case loses its original property and cannot represent a corrosion hazard for steel [14].

In this way, the data obtained indicate that ferrocene and its derivatives are promising compounds for protecting carbon steels from corrosion and biofouling in non-aggressive 
environments. At the same time, they can be introduced as corrosion inhibitors, as well as reliable anti-corrosion coatings.

\section{References}

1. A.F. Alimov, Introduction to Production Hydrobiology (JL: Gidrometeoizdat, 1989)

2. Journal of General Biology 58 (3), 27-42 (1997)

3. A.F. Alimov, Ecology 1, (1975)

4. A.F. Alimov, Mollusks. Ways, methods and results of the study 4, 70-72 (1971)

5. A.F. Alimov, Journal of General Biology 30 (5), 621-631 (1969)

6. T.P. Hoar, J.M. West, Nature 181 (4), 835-841 (1958)

7. A.F. Alimov, Basic concepts of production hydrobiology (Determination of the aquatic communities' production. Educational and methodical literature, Nauka, Novosibirsk, 2000)

8. F.M. Mikheeva, G.M. Florianevich, Ya.M. Kolotyrkin, F.Ya. Frolov, Protection of metals 23 (6) 915-921 (1987)

9. N.D. Gomatov, N.I. Zhuk, V.A. Ritov, M.A. Vedeneeva, Laboratory work on corrosion and protection of metals (M.: 1961)

10. L.P. Vershinina, Investigation of the kinetics and mechanism of electrode processes by the method of continuous renewal of the metal surface under the solution. Sat. New Methods for Researching Corrosion of Metals, (Edited by I. L. Rosenfeld, Nauka, Moscow, 1973)

11. Ya.M. Kolotyrkin, Protection of metals 3 (2), 131 - 144 (1967).

12. A.I. Freiman, V.A. Makarov, I.E. Bryksin, Potentiostatic methods in corrosion research and electrochemical protection (Chemistry, Moscow, 1972)

13. E.V. Fedulova, T.K. Peretz, A.G. Timofeev, S.Yu. Kubarev, Yu.A. Vorontsov, I.V. Makhiboroda, A.V. Moskvicheva, Improving the method of protection against corrosion of grids of the head of water consuming facilities (Almanac-2019-1, edited by G.K. Lobacheva, VolSU Publishing House, Volgograd, 2019) Pp. 343-347.

14. G.T. Burstein, G.W. Ashley, Corrosion 39 (6), 241-247 (1983) 